\title{
The Planning Practice Study of Urban Green Space System in High-Density Urban Areas Based on the Concept of Ecological Restoration and Urban Repairing
}

\author{
LI CHEN ${ }^{1,}$, , ZENG YUN ${ }^{2, b}$ \\ ${ }^{1}$ Tianjin Urban Planning and Design Institute, D2101. Tower A. No. 89 Huangpunan Road. Hexi \\ District. Tianjin, China \\ 2 Tianjin University School of Architecture, No.92 Weijin Road, Nankai District. Tianjin, China \\ alechen0520@163.com, b530263920@qq.com
}

\begin{abstract}
Keywords: Urban High-Density Area, Green Space Network Design, Planning Practice, Ecological Restoration and Urban Repairing

Abstract. Accompanied by China's New Normal Economy and Chinese social and economic transition. The urbanization has entered a new stage of improving quality and increasing efficiency as the main development, meaning that future urban construction shall not only focus on newly increased lands only, but also focus on better utilizing the existing resources of built-up areas and effective utilization of such resources. Urban railway lines, with traditional freight transport as the main function, are important existing resources. They used to make tremendous contributions to the industrial development of cities. However, they have gradually declined with upgraded industries in various cities. In addition, restrained by resources and environment, the network in the planning is difficult to implement in reality for the greenspace systems in high-density urban areas. As a result, how to better utilize existing resources and rebuild greenspace networks, cope with multi-component space demands with finite space resources have been an important issue for the ecological restoration and urban repairing of high-density urban areas. Based on this, typical high-density urban areas were taken as the research object with fully excavate the spatial potential of existing resources represented by abandoned railways, combine the network design of urban green space systems with important linear spatial elements and features, apply the planning strategies of "greening railways and linking river", "revitalizing railways and connecting urban areas" and "inheriting railways and boosting industries", and explore the important values of existing resources by reconstructing and perfecting the green space system in high density area. So as to sew up the wound of urban human ecological environment, link the patterns of urban economic ecological, and establish the new structure of ecology in high-density urban areas with a systematic manner.
\end{abstract}

\section{Introduction}

Accompanied by the transition of China's social economy, urban construction also transfer from the rapid growth and rough expansion to the internal development mode for quality enhancement. Urban railway lines have made a great contribution to the rapid development of industrial construction in traditional industrial-based central city. However, the railways are now facing displaced or abandoned surrounded by the urban construction areas with the rapid expansion, and turn into the important factor to separate urban spaces into pieces. An important issue for the city managers and planners to deal is how to remain such large-scaled and important city-level stock remains located in city center. On the one hand the railways are dead area and affect the quality of life, and on the other hand influenced by land ownership, administration, scale and miscellaneous factors, the effective updating measures unable to carry out. This article attempts to consider the potential of renewable space in city center on the basis of the loop of railways in Tianjin, combined with the plan of "the Round-the-City Railway Park Planning in Tianjin" and "Enjoy the Green Loop in Tianjin-City Vitality Improvement Project", explore the effective way to promote the construction of "natural ecology, human ecology, and economic ecology" in city's ecological system, and practice the new concept of "ecological restoration and urban repairing". 


\section{Background}

Historical Evolution - Witness the Important Context of Urban Development. Tianjin is the cradle of China's railway culture and also the birthplace of light industry in modern China. In the 1880 s, Tianjin took the lead in entering the railway transportation era nationwide, and also constructed the first self-built standard gauge railway_- the Tangshan-Xu Gezhuang Railway, and by the 1970s, More than 100 industrial railway lines had been constructed in Tianjin, the railway lines formed a unique loop in the central district, surrounding the ring gathered a large number of factories, warehouses and workers' communities. But nowadays most railway lines are idle and abandoned, and become the dead area in city center district. The abandoned railway lines not only cause the waste in land resources and hinder the development of surrounding areas, which damaging the city image and internal vitality. Carding the history, the loop of the railway lines in Tianjin carries the history of industrial development, and witness the important context of urban development.

Current Situation - the Idled Urban Resource. The loop of the railway lines in Tianjin consist mainly by six parts, which are under different railway bureau jurisdiction. The total length of the loop is about $65 \mathrm{~km}$, across 7 administrative regions in Tianjin. The loop also represent the important space carrier for future urban construction and development. Within 1 kilometer along the loop, gathered about 1 million size of the resident population, the surrounding lands resources compound different functions, such as residence, park, commercial and business. But these lands are cut into pieces by the railways, and along the loop there are still 91 small pieces of unused land, the loop railway is also connected large public service facilities in series such as railway station, Tianjin Olympic Centre, convention center and so on. Meanwhile, the environment resources around the loop are also variegated, which include the largest wetland park in urban area of Tianjin 、 part of the Haihe river which is the largest river system in north China and other seven large city parks and four rivers of urban ecological network resources.

By sorting out the status quo, the loop of the railway is an important stock remains in the city and the value is often underestimated. By making full use of the railway lines, like a lever, can lever and integrate different resources in urban area.

\section{The Problem Analysis}

The Negative Effects are Numerous and the Intention is Weak. In the process of rapid urban expansion, Due to the history, social, economy, property rights and many other factors, the abandoned railway did not get effective and timely planning and management. As a result, the use of railway becomes a blind spot in urban design. According to incomplete statistics, at present, there are nearly 100 abandoned railways in China's major cities (Wang Jing, Xiang Yang, Luo Yanyun, 2010) ${ }^{1}$.and the abandoned railway area is a typical representative of serious pollution and layout disorder, most of the abandoned railways are deserted for no one cares about (Pan Liu, 2014) ${ }^{2}$. The effective utilization for abandoned railway frequently choose to direct demolition instead of suffering from the stress. However, the abandoned railway space is an important cultural mark and public resource of the city. The problem that abandoned railways bring ultimately due to the planning management untimely and objective differences in property rights. It is not caused by the defects of the railway space itself. By tearing down the railways can certainly solve the negative problems, but it will also lose the potential opportunities for the city at the same time. The loop of the railway lines, which regarded as a city-level stock remains and witness the development of Tianjin, should learn the benefits from the high-line park in New York by the way to become a public product to promote the city image and citizen happiness. Instead of repeating the tragedy of Beijing city wall which has the opportunity be the world's first high-line park but turned out to be the world's most congested third ring $\operatorname{road}\left(Z h a n g\right.$ Yuxing,2016) ${ }^{3}$.

Underrated Value of the City. Limited to the classic cases in the railway reformation, the most common way of railway reconstruction is designed to the landscape greenway, which ignores the 
different scale between the different railways to the city value. It is true, such as Xiamen railway cultural park and other railway reconstruction cases, through the rich ecological landscape design, effectively changed the role of abandoned railway in urban environment, created a new city culture card, and revitalized a new life to the city. But limited to characteristics in the size and fragmented space, such a small abandoned railways can transform with the target of low cost, fragmented and easy to build. However, when running into dozens of kilometers of the railways in city, the renewal and reuse should not only limited concentrate on the environment optimization and also on promoting the intrinsic value. Cities as the most concentrated place for human economic and social activities, is a typical social-economic-natural complex ecosystem. Therefore, the reuse of the abandoned railway lines need to fully understand the status quo and future expectation of the urban public resources. Re-excavating the value of abandoned railway in urban natural ecology, humanistic ecology and economic ecology, and develop the function of "connecting and communicating with the city".

\section{Systematic Construction of the Green Space System in High-Density Area under the Concept of Ecological Restoration and Urban Repairing}

During the important period of urban development and transformation, responding to the concept of "Ecological Restoration and Urban Repairing" in China's Central Urban Work Conference. Fully exploring the potential of abandoned railway space resources, based on the method of "micro-updating", forming a complexed of humanistic, economic, and ecological corridor by integrating ecological river channels, cultural resources, idle lands and public spaces along the railway lines in city center.

Reshape the Urban Natural Ecology. A natural ecological railway green park will be built by using abandoned railway lines under the principle of basically unchanged property rights operated through the coordination and cooperation of government, which can reduce the cost due to ownership transactions. The way of reusing the railway lines fully respect and improve the existing ecological environment by ecological green planting along the line, the loop of railway lines connects the green space in city center such as existing urban rivers, parks, small scattered green areas, etc. and replenishes and optimizes the city's blue-green network to improve the capacity of water conservation and purification. In addition, the spread railways, combined with the city's slow walking and bicycle path, enriching the way of ecological transportation to form a perfect open natural ecological network.

Create the Urban Human Ecology. The green ring in the central city should take the railway trail as a clue, which focus on fully excavate the humanistic value along the railway line, and keep the railway elements such as sleepers, pillow stones, traffic lights, railway tracks and so on, so as to strengthen the slow system of the railway trail. Meanwhile, the planning of the green ring takes the railway as the space carrier, join designers and the enterprise strength by introducing the concept of community building, so as to operate the sustainable creative action in urban space, and guides residents to participate in and community updating spontaneously, gradually enriches the functions of cultural, creative, and exhibition to perfect public services along the line and create a vibrant urban humane ecological network.

Link the Urban Economic Ecology. Based on the green ring of the railway park, though the design of slow system to maximum connect with each functional group and guide the positive space of city life. Simultaneously, the functional and space structure along the railway should be adjusted appropriately to enrich land functions and enhance the value of the land, the urban green economic growth belt will be formed to promote the development of urban economic and ecological network.

\section{The Practice in Tianjin}

Greening railways and linking the river. As the implementation of policies required by the urban development, the railways and lineside industrial premises of the railway that circles central area of Tianjin has gradually fallen to disuse and become a dead angle of weeds and wastes with years 
of industrial pollution to the surroundings. The city planning proposed the ecological transformation for abandoned railways that bears memory of the modern Chinese industry named "the Round-the-City Railway Park Planning in Tianjin". The planning use the disused railways as the medium, approximately 1.26 square kilometers of protective green land along the belt will be transformed into a continuous urban park, the newly added urban green space will be approximately 1.24 square kilometers. In addition, the ecological transformation of the green ring has retained more than 22 kilometers of old railways, the scarred city image will be changed by carrying on the landscape design using railway elements such as sleepers, and railroad tracks which can highlight the characteristics of railway culture and enrich cultural landscape connotation (Tianjin Urban Planning $\&$ Design Institute, 2013) ${ }^{4}$. Besides reshaping the image of the city, the plan relies on the green ring formed a city-level open space which set functions of "ecological conservation, industrial culture, and public services" as one integrated. The ring also run through seven main areas in Tianjin which total length is 45 kilometres, the average width is 100 meters, and cascades 18 scattered green space. A blue-green network in the central city should be built through the link of urban rivers. A new eco-network structure of "two rings and four actinomorphic axes" in downtown Tianjin should be established combined with the green loop (Fig. 1), the ring help to conserve urban water resources, enrich urban landscapes, perfect the green space system and improve the quality of urban ecosystem.

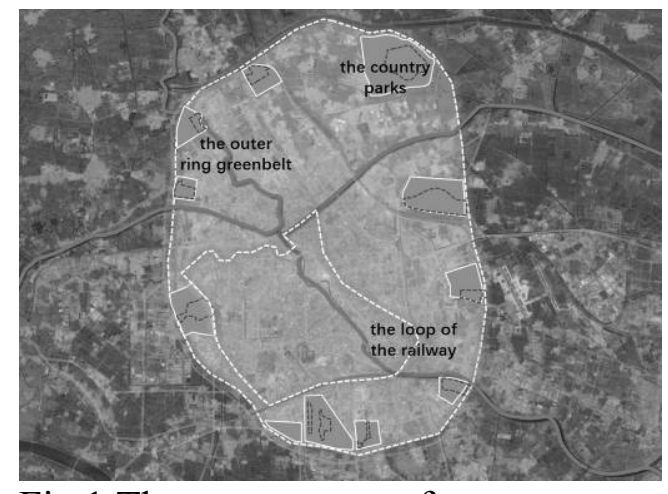

Fig.1 The new pattern of green space system

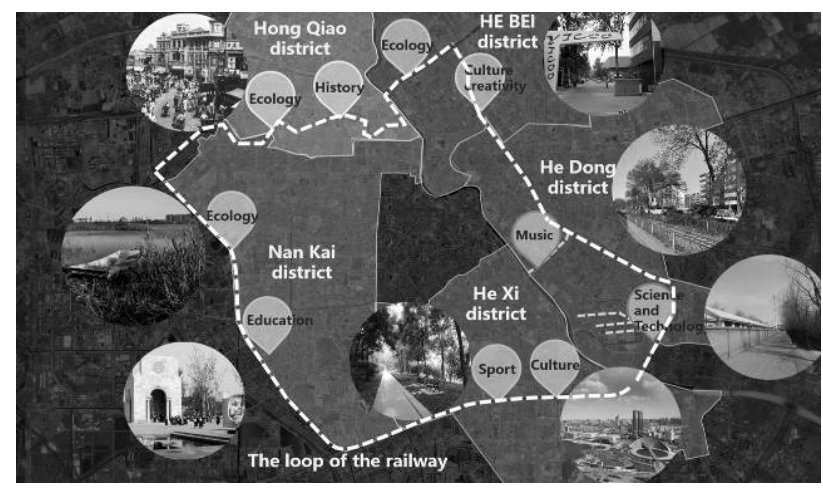

Fig.2 Encourage different team to participate

Revitalizing railways and connecting urban areas. Besides the reconstruction of the spatial image and the construction of green belts, more attention should be paid to vitality enhanced of the community space, and the public space benefits and opportunities for urban events brought by reusing the abandoned railways. There are 69 mature communities along the green loop, with a total of 840,000 urban residents. Another plan proposes the concept of community building named "Enjoy the Green Loop in Tianjin - City Vitality Improvement Project". Instead of community separation, the green loop links various communities though sharing public activity space with "creative planning, meticulous activities, and innovative space" (Chang Yanxun, 2016). The plan of Enjoy the Green Loop adds was firstly proposed the power of designers and enterprises to guide residents to participate in (Fig. 2), in order to operate a diversified and dynamic space, ensure the long-term popularity and create a communion of urban humanities and ecology. With the project to build a cooperation platform consist of enterprises funds and commercial brands, the railway transformation and operational upgrading can be realized in a participatory manner. Business activities should be carried out randomly in the railway area to create events, raise more awareness of the railway. While promoting the designers independently design urban works, the plan also encourage the team of designers who assist residents in community updating. In order to form a renewal dominant force consists by the surrounding residents, and the bottom-up renewal force will guide continuous transformation and renewal of its surrounding communities. The huge public benefits from the renewal obviously gather urban resources and form the multiple functional structure of the city to ensure continuous outputting energy for the city (Tianjin Urban Planning \& Design Institute, 2017).

Inheriting railways and boosting industries. The plan of "the Round-the-City Railway Park Planning in Tianjin" improves and optimizes the spatial image of the city and rebuilds the natural 
corridor of the city is designed by ecological way, the other plan "Enjoy the Green Loop in Tianjin-City Vitality Improvement Project" gathers and gives the urban vitality to the ring railway, and creates a public space of humanistic ecology. The process of the abandoned railways transformed into the linear spatial wealth promoted the value of land. About 11.47 square kilometers of idle land along the green ring provides adequate space for the plan. The urban corners that were scattered have become the important land resources that complement the urban public service facilities and enhance the vitality of railway space. At the same time, the renewal and utilization of the green loop has promoted the renewal of industrial remains along the railway lines. The ecological transformation and the infusion of vitality given to the railways have changed the back-faced relationship between the railways and the communities nearby, promoted the self-upgrade, implanted composite functions of the old communities. In addition, the green loop optimized the public facilities and promoted the investment along the line which links one main axis, one main and two sub centers, ten key projects in Tianjin. A multiple and complex growth economic belt has formed which improves the value of urban land, guides the updating of land and interconnects the urban economic ecological pattern.

\section{Conclusion}

As the city has developed into a stage that focuses on both growth and the remains, the urban railway, which once made great contributions to the industrial development, has changed to a key cause of the fragmented urban spaces in the downtown area. Based on the idea of Ecological Restoration and Urban Repairing, this article aims to explore the abandoned railways space, make best of linear urban spaces and proposes planning strategies, to explore paths to construct the urban green space system in high-density urban areas from three aspects of "natural, humanistic and economic ecology", and make efforts to re-shape the space and improve city vitality through the implementation of the planning, so that adverse conditions can be changed into favorable ones, damages to the city's ecological environment can be remedied, the fragmented environmental and humanistic pattern can be corrected, the economic and ecological patterns of the city can be linked, and the ecological pattern for a densely populated city can be systematically constructed.

\section{Acknowledgements}

This work was financially supported by the National Key point Research and Invention Program of the 13th Five-Year (2016YFC0502903).

\section{References}

[1] Wang Jing, Xiang Yang, and Luo Yanyun: Discussion on the Planning Strategy of Disused Railways Basing on Greenway Theory [J]. Northern Horticulture Vol.129-132 (2010)

[2] Pan Liu: Analysis on renovation method of city abandoned railway [J]. Shanxi Architecture Vol.5-6 (2014)

[3] Information on http://www.weixinnu.com/tag/article/3951937744.2016

[4] Information on http://www.yangqiu.cn/zhongshun98/679572.html

[5] Chang Yanxun, Li Fang, and Zhao Xianyue: Study on Evaluation Indexes of Land Use Efficiency around Urban Railway Greenway-Take Tianjin Railway Greenway Park as an example [M]. China Urban Planning Annual Conference (2016).

[6] Tianjin Urban Planning \& Design Institute: Enjoy the Green Loop in Tianjin - City Vitality Improvement Project [R]. (2017) 